\title{
Adherence to Treatment by Patients with Type 2 Diabetes Mellitus at Monze Mission Hospital, Monze, Zambia
}

\author{
Sanford Nyirongo*, Patricia Katowa Mukwato, Emmanuel Mwila Musenge, \\ Victoria Mwiinga Kalusopa
}

School of Nursing Sciences, University of Zambia, Lusaka, Zambia

Email: *snyirongo@ru.edu.zm

How to cite this paper: Nyirongo, S., Mukwato, P.K., Musenge, E.M. and Kalusopa, V.M. (2021) Adherence to Treatment by Patients with Type 2 Diabetes Mellitus at Monze Mission Hospital, Monze, Zambia. Open Journal of Nursing, 11, 184-203. https://doi.org/10.4236/ojn.2021.113017

Received: January 7, 2021

Accepted: March 27, 2021

Published: March 30, 2021

Copyright $\odot 2021$ by author(s) and Scientific Research Publishing Inc. This work is licensed under the Creative Commons Attribution International License (CC BY 4.0).

http://creativecommons.org/licenses/by/4.0/

\section{(c) (i) Open Access}

\begin{abstract}
Background: Diabetes mellitus (DM) is one of the most common noncommunicable diseases and among the leading causes of disability, morbidity and mortality globally. The study assessed adherence to treatment by type 2 DM patients aged 20 years and above at Monze Mission Hospital in Monze district, Zambia. Research questions: 1) What is the level of adherence to treatment by type $2 \mathrm{DM}$ patients receiving care from Monze Mission Hospital? 2) What factors influence adherence to treatment by type 2 DM patients?
\end{abstract} Methods: The study was conducted in 2017. It was a cross-sectional design. Simple random sampling method was used to select respondents and data was collected using a structured interview schedule. Data was entered and analyzed using the modified self-reported Morisky Medication Adherence Scale with six scores, modified self-care management questionnaire and $\mathrm{IBM}^{\circ}$ Statistical Package for Social Sciences. Chi-Square was used to test associations between variables and binary logistic regression was used for multivariate analysis. The Morisky Medication Adherence scale was interpreted as follows: patients who scored between 4 - 6 points on knowledge had high knowledge while those who scored between $1-3$ points had low knowledge about the disease. Results: The sample size of the study was 138 respondents. The study showed, only $44.2 \%$ of respondents had good adherence to treatment as they scored above 4 using the Morisky Medication Adherence Scale. Majority of the patients (55.6\%) had knowledge about treatment despite $65.2 \%$ of respondents reported distance and financial challenges as hindrances to adherence. The study revealed a statistical association between adherence and knowledge of type 2 DM treatment. Conclusion: The study showed that poor adherence to treatment reduced as knowledge about DM 
increased. There is need to consider educational programs to strengthen adherence to dietary advice, regular exercise and follow up, to achieve normal glycemic levels.

\section{Keywords}

Adherence, Knowledge, Lifestyle, Self-Management Support, Treatment, Type 2 Diabetes Mellitus Patients

\section{Background}

Diabetes mellitus (DM) is a metabolic disorder of carbohydrates, proteins and fats characterized by hyperglycemia, polydipsia, polyphagia, polyurea and weight loss due to defects in insulin secretion, insulin action, or both [1]. It is a major public health problem worldwide, which requires continued medical care and ongoing patient self-management, education and support to prevent acute and to reduce the risk of long-term complications [2]. It is one of the most common non-communicable diseases and the fifth leading cause of disability, morbidity and mortality globally especially in developing and newly industrialized nations [3] [4].

Type $2 \mathrm{DM}$ results predominantly from insulin resistance or insulin deficiency to primarily insulin secretory defect characterized by hyperglycemia. It starts late (mostly early 40s) in life and can go unnoticed and undiagnosed for years. It accounts for $90 \%-95 \%$ of patients with diabetes worldwide and those affected are unaware that they have the condition. Due to its progressive nature, most patients with type 2 diabetes eventually require insulin to achieve and maintain glycaemic control [5].

The major challenges experienced by type $2 \mathrm{DM}$ patients are centered on adherence to recommended treatment. García-Pérez et al. and Likitha et al. [3] [6] defined adherence to therapy as the extent to which a person's behavior in taking medication, following a diet, and/or executing lifestyle changes, corresponds with agreed recommendations from a healthcare provider.

The prevalence of type $2 \mathrm{DM}$ is rapidly increasing all over the world with the number of adults with the disease rising from 135 million in 1995 and is projected to be 300 million in the year 2025 [2]. The most affected people are aged between 40 and 59 years [3]. However, facts sheet [7] showed that 422 million people were already suffering from type 2 DM by 2014 with the global prevalence of $8.5 \%$ among adults over 18 years of age in the same year. Recent studies have also shown a high DM prevalence in low and middle-income countries of Sub-Saharan Africa including Zambia, where the diabetes population has drastically increased from an estimated 98,000 patients in 2000 to about 1.5 million in 2010 from a population of 30 million people [1] [7]. In 2016, an estimated 1.6 million deaths were directly caused by diabetes [7]. WHO estimates that diabetes was the seventh leading cause of death in 2016 although the onset of type 2 di- 
abetes can be prevented by a healthy diet, regular physical activity, maintaining a normal body weight and avoiding tobacco use [7]. Despite it being relatively easy to control its prevalence, most of the literature revealed shows that there is an enormous challenge regarding adherence to type $2 \mathrm{DM}$ management in many countries.

The American Diabetes Association (ADA) revealed that type 2 DM patients sought treatment due to symptoms of marked hyperglycemia, polyuria, polydipsia, weight loss, polyphagia and blurred vision and sometimes a comatose state despite being on recommended treatment [1]. Glycated haemoglobin (HbAlc) is the best measure of glycaemic level over the previous three months because it reflects the glucose levels the red blood cell was exposed to over a period of $8-12$ weeks during its life cycle, thus providing a useful longer-term gauge of blood glucose control. Diabetic patients with a glucose measure of $\leq 48 \mathrm{mmol} / \mathrm{mol}$ (6.5\%) are said to have good blood glucose control and it is the set target for monitoring patients with well-controlled glucose levels [8]. Another study further stated that $\mathrm{HbAlc}$ of $\leq 48 \mathrm{mmol} / \mathrm{mol}$ has shown to reduce microvascular complications of DM and if implemented soon after diagnosis, it is associated with long-term reduction in macrovascular disease [5].

The clinical goals for diabetes outcomes are not routinely achieved in practice due to patients' poor adherence to type $2 \mathrm{DM}$ treatment and lack of equipment to measure HbA1c. Barriers to accessing treatment from health institutions by patients as well as lack of readily available diagnostic equipment and drugs have to a large extent led to many patients experiencing poor glycaemic control at home [9].

In the United Kingdom, there were 150,000 newly diagnosed people with type $2 \mathrm{DM}$ in 2010, bringing the number of people known to have the condition to 2.78 million. About a million more were unaware that they already had diabetes and many were only diagnosed after having the condition for many years, when complications had already set in [9]. Additionally, there has been a global shift in the populations affected with type $2 \mathrm{DM}$. South-East Asia has become an emerging epicenter of this chronic condition with 138 million of all adults with the condition in the world living in this region [10]. The projections depict that the number of people with type $2 \mathrm{DM}$ in the region will increase to 220.9 million of the adult population by 2030 [9] [10]. Some studies revealed that an overwhelming burden of the disease is found in low and middle-income countries [10]. The International Diabetes Federation (IDF) further found that African region, has the highest proportion of undiagnosed type $2 \mathrm{DM}$ which at $63 \%$ of 19.8 million adults. An estimated 522,600 people in the region died from type $2 \mathrm{DM}$ related causes in the same year representing $8.6 \%$ of deaths from all causes in adults. This could be attributed to poor adherence to DM treatment [10].

Type $2 \mathrm{DM}$ is currently the most common form of diabetes in sub-Saharan Africa, similar to other regions of the world [11]. The prevalence of type $2 \mathrm{DM}$ in the region in 2010 was $10.4 \%$ [12]. The projected increase come with its own challenges related to limited infrastructure and poorly equipped health institutions to manage this epidemic in many countries. This may be due to lack of 
knowledge on healthy nutrition and better healthy lifestyles which can help to delay the development of the disease.

Other studies conducted in Mozambique and Zambia showed that availability of insulin in health institutions in Mozambique was better compared to the Zambian hospitals and health centers in three provinces (Lusaka, Eastern, and Copperbelt) with results showing drug stock out at the time of the study [13]. This could be one of many factors which impede adherence to diabetes type 2 treatment and subsequently exposes patients to diabetic complications and sometimes death. A study revealed that there were 1839 (1.36\%) deaths due to type $2 \mathrm{DM}$ in Zambia with the age adjusted death rate of $35.64 \%$ per 100,000 of population [7]. It is evident that type $2 \mathrm{DM}$ is on the rise and control measures to non-adherence related complications can be enhanced through educating patients on the importance of adhering to treatment to prevent DM related deaths due to complications.

Similarly, the number of patients with type $2 \mathrm{DM}$ being attended to, at Monze Mission Hospital in Southern province is likewise on a steady increase. In the years, 2013, 2014 and 2015, Monze Mission Hospital had 107, 139 and 198 admissions of new and old type 2 DM patients respectively [14]. Patients' records from the institution furthermore revealed that, patients who sought medical treatment presented with elevated blood glucose levels. The reason for elevated glucose levels in these patients is not clearly understood despite patients being on treatment. This situation compelled the researcher to undertake the study on adherence to type $2 \mathrm{DM}$ treatment.

\section{Methodology}

\subsection{Study Design}

A cross-sectional study design was used to obtain quantitative descriptions among variables without attempting to infer causal connections on adherence to treatment by patients with type $2 \mathrm{DM}$.

\subsection{Study Setting}

The study was undertaken in 2017 at Monze Mission Hospital in Monze district. The hospital services a population of 214,557 , though other districts in the province refer their patients to the institution. It offers second level health services such as medical, surgical, obstetrics, gynaecology services and has a well -established an Antiretroviral Therapy clinic.

\subsection{Study Population}

The study population were type 2 DM patients DM aged 20 years and above who accessed medical treatment at Monze Mission Hospital.

\subsection{Sample Selection}

A simple random sampling method was used to choose patients using a sam- 
pling frame for eligible type $2 \mathrm{DM}$ patients who sought medical care from the Out-patient medical clinic and those admitted. The sampling frame comprised of 216 type $2 \mathrm{DM}$ patients who accessed health care services during the three months of data collection. One piece of paper was picked at a time without replacement after shaking the box until the patients were selected per day and the required sample size for the study was reached. To eliminate selection biases, patients were identified and recruited consecutively for three months.

\subsubsection{Inclusion Criteria}

All admitted and outpatients with type 2 DM patients aged 20 years and above, on treatment for type $2 \mathrm{DM}$ for more one year.

\subsubsection{Exclusion Criteria}

The study sample excluded very ill type $2 \mathrm{DM}$ patients and those who were less than one year on treatment.

\subsection{Sample Size}

A sample size of patients was calculated using Krejcie and Morgan (1970) formula for calculating sample size of a finite population. A total sample size of 138 patients was recruited to the study.

$$
\begin{gathered}
S=X^{2} N P(1-P) \div d^{2}(N-1)+X^{2} P(1-P) . \\
X=1.96 ; N=216 ; P=0.5 \text { and } d=0.05 \\
S=\frac{1.96^{2} \times 216 \times 0.5(1-0.5)}{0.05^{2}(216-1)}+1.96^{2} \times 0.5(1-0.5) \\
S=138 .
\end{gathered}
$$

\subsection{Data Collection}

A structured interview schedule was used to collect data. The schedule had five sections. Section A had demographic data; section B assessed the health care system, Section C assessed patients' knowledge on DM. Section D assessed the patients' adherence to treatment using a modified self-reported Morisky Medication Adherence Scale and section E assessed the attitude of patients on self-management. The tool was convenient for both the literate and the illiterate patients and increased objectivity of data collection.

\subsection{Ethical and Cultural Considerations}

Ethical clearance was sought from the University of Zambia Biomedical Research Ethics Committee (Ref: 012-04-17) before having contact with respondents. Permission to conduct the study was further obtained from Monze mission hospital management. Respondents were not subjected to any physical harm as the study did not involve any invasive procedures. Those who declined to participate were reassured that no privileges would be taken away from them. Those who agreed to take part in the study were requested to sign a consent 
form as a way to authorize participation in the study. Participants were assured of anonymity and confidentiality by interviewing them in privacy individually as well as ensuring that participants' names did not appear on the interview schedules. No other person apart from the researcher and research assistants were allowed to have access to the research data.

\subsection{Statistical Analysis}

Data was collected, coded, entered and analyzed using the IBM ${ }^{\circ}$ Statistical Package for Social Sciences (SPSS ${ }^{\circ}$ ) for Windows version 24. A Chi-square test was used to test associations between predictor and outcome variables. The Confidence Interval (CI) of $95 \%$ was set, a p-value of $<0.05$. The binary logistic regression was used for multivariate analysis to determine true predictors of adherence to DM treatment recommendation. The omnibus test of model coefficients $\left(\mathrm{X}^{2}=\right.$ 5.742; $\mathrm{p}=0.219)$ and Regression Model were used to determine prediction accuracy of the independent variable. The predictors considered statistically significant were computed into the Regression Model to control for confounders.

\section{Results}

This paper presents data collected from 138 type 2 DM patents aged between 20 and 60 from outpatient department and admitted patients to the medical ward at Monze Mission Hospital, Zambia.

\subsection{Socio-Demographic Data}

This study showed that the majority $(58.7 \%)$ of the patients in the study were females. The age range was between 20 and 68 years and 27.5\% (38) of the respondents were aged between 40 - 49 years while 29\% (41) of patients were aged 60 years and above. Slightly less than half of the patients (63\%) were married and $21.7 \%$ were widowed. Less than half of the patients $(47.9 \%)$ had secondary education. Further, $40.6 \%$ of the patients were self-employed/Businessmen and only $29 \%$ were civil servants (Table 1 ).

\subsection{Patients' Attitude towards Type 2 DM Treatment}

This study established that most of the patients (59.4\%) had poor attitude to self-care management while $(40.6 \%)$ reported good attitude. Furthermore, it was found that, the majority of the patients $(65.9 \%)$ forget to take their medication. More than half of the patients (58.7\%) reported stopping taking their medications without informing the doctor because they felt worse when they took the drugs and $55.8 \%$ of the patients also forgot to carry along their medicine when they travelled. Slightly more than half of the patients $(55.1 \%)$ felt distressed about adhering to their treatment plan and $44.9 \%$ followed their treatment plan (Table 2). The majority (56.5\%) of the patients reported poor adherence to type 2 DM treatment while slightly less than half (43.5\%) revealed good adherences to 2 DM treatment (Figure 1). 


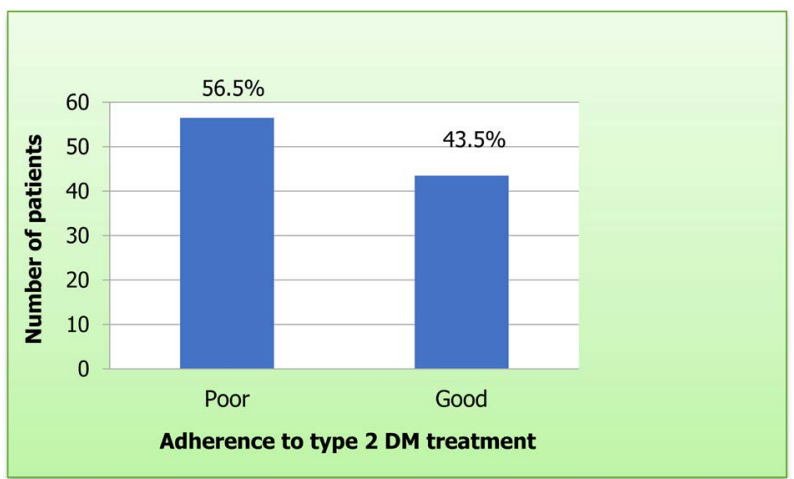

Figure 1. Patients' adherence to type 2 DM treatment $(n=138)$.

Table 1. Demographic characteristics of the patients $(n=138)$.

\begin{tabular}{|c|c|c|}
\hline Characteristics & Frequency & Percent \\
\hline \multicolumn{3}{|l|}{ Sex } \\
\hline Male & 57 & 41.3 \\
\hline Female & 81 & 58.7 \\
\hline Total & 138 & 100.0 \\
\hline \multicolumn{3}{|l|}{ Age } \\
\hline $20-29$ Years & 14 & 10.1 \\
\hline 30 - 39 Years & 15 & 10.9 \\
\hline $40-49$ Years & 38 & 27.5 \\
\hline $50-59$ & 31 & 22.5 \\
\hline 60 Years and above & 40 & 29 \\
\hline Total & 138 & 100.0 \\
\hline \multicolumn{3}{|l|}{ Marital status } \\
\hline Single & 18 & 13 \\
\hline Married & 87 & 63 \\
\hline Widowed & 30 & 21 \\
\hline Divorced & 3 & 2.3 \\
\hline Total & 138 & 100.0 \\
\hline \multicolumn{3}{|l|}{ Education level } \\
\hline No formal education & 8 & 5.8 \\
\hline Primary school & 50 & 36.2 \\
\hline Secondary & 66 & 47.9 \\
\hline Tertiary & 14 & 10.1 \\
\hline Total & 138 & 100.0 \\
\hline \multicolumn{3}{|l|}{ Occupation } \\
\hline Civil servant & 40 & 29.0 \\
\hline Self-employed/ Businessman & 56 & 40.6 \\
\hline Retired & 25 & 18.1 \\
\hline Un employed & 17 & 12.3 \\
\hline Total & 138 & 100.0 \\
\hline
\end{tabular}


Table 2. Patients' attitude towards adherence to treatment $(n=138)$.

\begin{tabular}{ccc}
\hline Characteristics & Frequency & Percent \\
\hline Forget to take your medication & 91 & 65.9 \\
Yes & 47 & 34.1 \\
No & 138 & 100.0 \\
Total & & \\
Had stopped taking medicine without telling the doctor & 81 & 58.7 \\
Yes & 47 & 34.3 \\
No & 138 & 100.0 \\
Total & & \\
Forget to carry medicine when going away from home & 77 & 55.8 \\
Yes & 61 & 44.2 \\
No & 138 & 100.0 \\
Total & & \\
Feel distressed about sticking to your treatment plan & 76 & 55.1 \\
Yes & 62 & 44.9 \\
No & 138 & 100.0 \\
Total & & \\
\hline & & \\
\hline
\end{tabular}

\subsection{Patients' Knowledge about Type 2 DM}

The respondents' knowledge on adherence in his study was assessed using a modified self-reported Morisky medication adherence scale with six points. This study shows that $(55.8 \%)$ were knowledgeable about type 2 DM treatment (Figure 2). It further revealed that, half (50\%) of the patients reported that they have been living with DM for 6 years and above while $32.6 \%$ have been living with DM for 2 to 5 years. The majority (58.7\%) of patients in the study have relatives suffering from DM. Most of the patients $(76.1 \%)$ did not know the antidiabetic drugs they were taking. Less than half $(44.2 \%)$ of the patients were on oral antidiabetic drugs, $26.1 \%$ were on insulin and $23.9 \%$ were on diet modification.

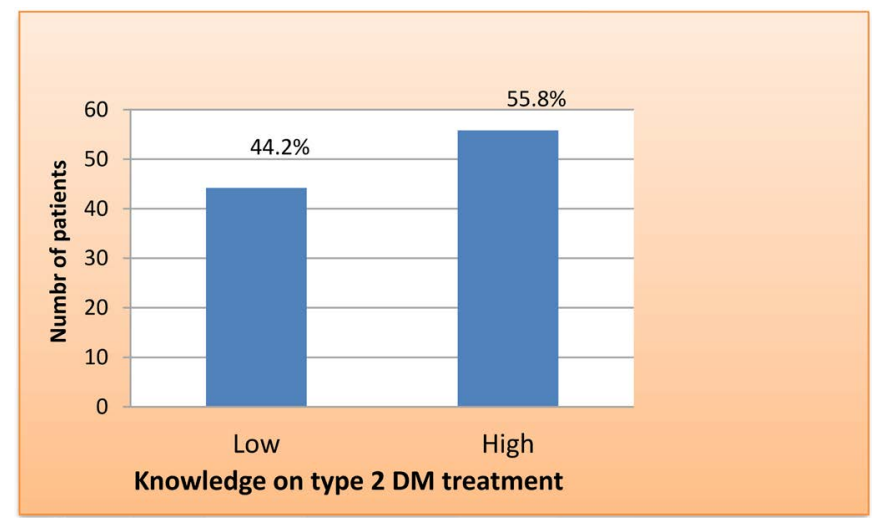

Figure 2. Knowledge about type $2 \mathrm{DM}$ treatment $(\mathrm{N}=138)$. 


\subsection{Patients' View on Health Care System}

The study shows that slightly more than half $(51.4 \%)$ of the patients reported that the health care system was poor. Most of the patients (65.2\%) indicated that they were reviewed every two months while $23 \%$ were reviewed after three months. The majority (63\%) of the patients reported frequent stock out of anti-diabetic drugs at the hospital. The study also shows that more than half (56.5\%) of the patients were not monitoring their blood glucose on daily basis because they did not have their own glucometers and monitored their blood glucose at public hospitals while only $7 \%$ of them monitored form private hospitals at fee. Many patients (60.1\%) live more than $5 \mathrm{~km}$ away from the hospital and use public transport to travel to the hospital, while $39.9 \%$ others cycled or walked to the hospital.

\subsection{Patients' Attitude to Self-Care Management}

This study established that most of the patients (65.3\%) were not checking and recording their blood glucose levels regularly. Additionally, 54\% of patients were not strictly following dietary recommendations by the doctor. However, half of the patients (50\%) kept doctor's appointment recommendations for DM treatment though the majority (59.4\%) of the patients were not taking medication as prescribed. More than half (52.2\%) of the patients were not performing regular physical activities to achieve optimal blood sugar levels (Table 3).

\subsection{Relationship between Adherence Type 2 DM Treatment and the Study Variables}

\subsubsection{Relationship between Adherence to Type 2 DM Treatment with} Knowledge about Type 2 DM Treatment

This study established that $51.9 \%$ (40) of the respondents who were adherent to type $2 \mathrm{DM}$ treatment had high level of knowledge about type $2 \mathrm{DM}$ treatment. Among those that were reported to be non-adherent, 67\% (41) had low knowledge of type 2 DM treatment. The report indicates that there was a statistically significant association between adherence to type $2 \mathrm{DM}$ treatment and knowledge about type $2 \mathrm{DM}$ treatment (p-value was 0.024 ). However, there were no significant associations between adherence to type 2 DM treatment and distance to the hospital, health care system and attitude to self-care management $(\mathrm{p}>0.05)$ (Table 4).

\subsubsection{Binary Regression Model}

This study further showed a positive correlation between knowledge of type 2 DM and adherence to treatment.

The regression model was statistically significant as a whole $\left(\mathrm{X}^{2}=5.085, \mathrm{p}\right.$ 0.024). A binary logistic regression test was used to determine the impact of (predictor variables) distance to the hospital, health care system, attitude towards self-care management and knowledge about DM treatment on (outcome variable) adherence to treatment of type $2 \mathrm{DM}$ patients. In terms of prediction power, the model could only account for $5.5 \%$ variation in the outcome variable 
and had a $78.2 \%$ accurate in predicting poor adherence and $40 \%$ accurate in predicting good adherence to diabetes treatment. Although, the study showed that education level was statistically insignificant $(p=0.346)$, good adherence increased from $32.8 \%$ to $51.9 \%$, while poor adherence dropped from $67.2 \%$ to $48.1 \%$ as knowledge on treatment increased from low to high. Data analysis with the binary logistic regression revealed that, changes in patients' knowledge from low to high on type 2 DM treatment would contribute significantly to the regression model $(\mathrm{p}=0.037$, odds ratio $=2.324)$, while changes in all other variables did not contribute insignificantly to the model (Table 5).

Table 3. Patients' characteristics on attitude to self-care management $(n=138)$.

\begin{tabular}{ccc}
\hline characteristics & Frequency & Percentag \\
\hline Attitude towards self-care management & & 40.6 \\
Good & 56 & 59.4 \\
Poor & 82 & 100.0 \\
Total & 138 & \\
I check and record blood sugar levels to achieve optimal & & 34.8 \\
glucose levels & & 65.3 \\
Applies to me very much & & 100.0 \\
Does not apply to me & 90 & 138
\end{tabular}

I choose food to eat to achieve optimal blood glucose levels

$\begin{array}{ccc}\text { Applies to me very much } & 82 & 59.4 \\ \text { Does not apply to me } & 56 & 40.6 \\ \text { Total } & 138 & 100.0\end{array}$

I keep all doctors' appointments recommended for DM treatment

$\begin{array}{ccc}\text { Applies to me very much } & 69 & 50 \\ \text { Does not apply to me } & 69 & 50 \\ \text { Total } & 138 & 100.0\end{array}$

I take my DM medicines as prescribed

$\begin{array}{ccc}\text { Applies to me very much } & 56 & 40.6 \\ \text { Does not apply to me } & 82 & 59.4 \\ \text { Total } & 138 & 100.0\end{array}$

I do regular physical activities to achieve optimal blood sugar levels

$\begin{array}{ccc}\text { Applies to me very much } & 66 & 47.8 \\ \text { Does not apply to me } & 72 & 52.2 \\ \text { Total } & 138 & 100.0\end{array}$

I strictly follow the dietary recommendation by the doctor

$\begin{array}{ccc}\text { Applies to me very much } & 63 & 46 \\ \text { Does not apply to me } & 74 & 54 \\ \text { Total } & 138 & \mathbf{1 0 0 . 0}\end{array}$


Table 4. Relationship between adherence type 2 DM treatment with associated factors ( $\mathrm{n}$ $=138)$.

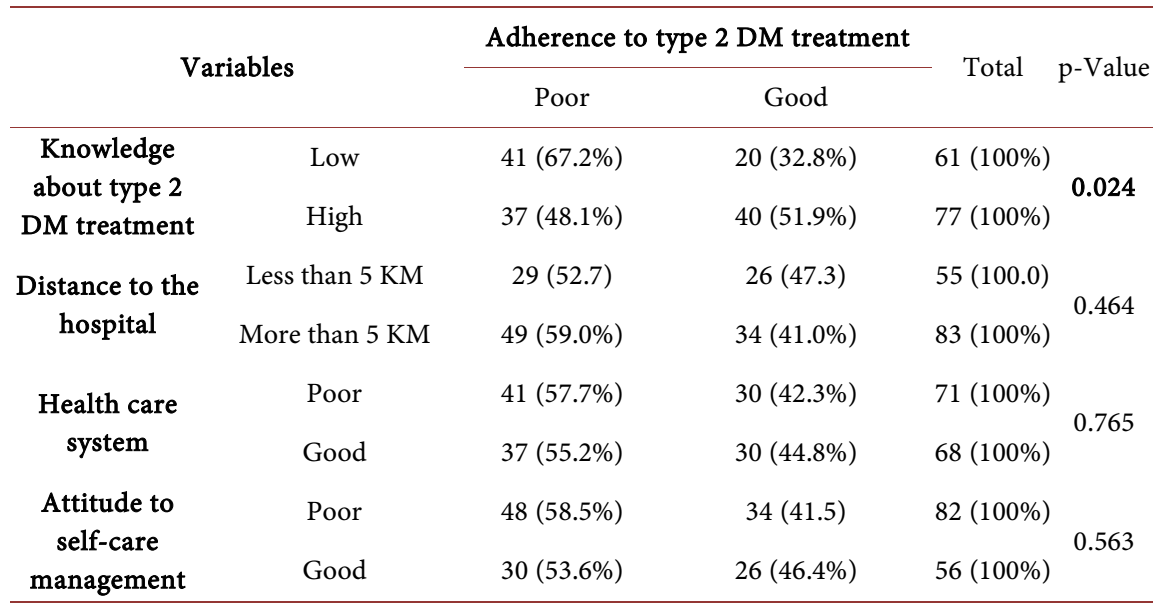

Table 5. Binary Logistic Regression determining factors associated with adherence to type 2 DM treatment.

\begin{tabular}{|c|c|c|c|c|}
\hline \multirow{2}{*}{ Variable Level } & \multirow{2}{*}{ P-Value } & \multirow{2}{*}{$\begin{array}{l}\text { Odd Ratio } \\
\text { (EXP (B)) }\end{array}$} & \multicolumn{2}{|c|}{ 95\% C.I. for EXP (B) } \\
\hline & & & Lower & Upper \\
\hline Gender (1) & 0.972 & 0.985 & 0.432 & 2.248 \\
\hline Gender & 0.00 & & & \\
\hline Age & 439 & & & \\
\hline Age (1) 30 - 39 Years & 0.349 & 2.325 & 0.397 & 13.603 \\
\hline Age (2) 40 - 49 Years & 0.569 & 1.614 & 0.311 & 8.366 \\
\hline Age (3) 50 - 59 Years & 0.991 & 1.010 & 0.182 & 5.594 \\
\hline Age (4) 60 Years and above & 0.665 & 0.676 & 0.115 & 3.982 \\
\hline Marital status & 0.959 & & & \\
\hline Marital status (1) Married & 0.592 & 0.699 & 0.189 & 2.583 \\
\hline Marital status (2) Widowed & 0.728 & 0.776 & 0.186 & 3.239 \\
\hline Marital status (3) Divorced & 0.789 & 0.654 & 0.029 & 14.657 \\
\hline Education level & 0.346 & & & \\
\hline Education level (1) Primary & 0.896 & 0.884 & 0.138 & 5.663 \\
\hline Education level (2) Secondary & 0.476 & 1.971 & 0.305 & 12.724 \\
\hline Education level (3) Tertiary & 0.908 & 1.137 & 0.128 & 10.079 \\
\hline Occupation & 0.532 & & & \\
\hline Occupation (1) Civil servant & 0.582 & 1.307 & 0.504 & 3.388 \\
\hline Occupation (2) Self-employed/ Businessman & 0.809 & 1.155 & 0.358 & 3.724 \\
\hline Occupation (3) Retired & 0.148 & 2.721 & 0.702 & 10.543 \\
\hline Distance to the hospital (1) $>5 \mathrm{KM}$ & 0.713 & 0.854 & 0.370 & 1.975 \\
\hline Knowledge (1) Low & 0.037 & 2.324 & 1.050 & 5.143 \\
\hline HealthCare (1) Poor & 0.624 & 1.224 & 0.546 & 2.746 \\
\hline Attitude (1) Poor & 0.747 & 1.139 & 0.517 & 2.512 \\
\hline Constant & 0.537 & 0.423 & & \\
\hline
\end{tabular}




\section{Discussions of Findings}

\subsection{Demographic Characteristics of the Patients}

The findings of the current study (Table 1), showed that more than half of the patients $(58.7 \%)$ were females and $41.3 \%$ were males. This could be attributed to good health seeking behaviours of women as opposed to men hence the increase in the number of females being treated for DM. Furthermore, culturally men are viewed as strong human beings; hence, if a man frequents the hospital, he is considered to be weak. Additionally, more than half of the patients (63\%) were married, while $(21 \%)$ were widowed. Of the patients, $29 \%$ were aged 60 years and above. This could be due to gestational DM which in most cases progresses to types $2 \mathrm{DM}$, hence the increase in the number of women seeking medical attention [15].

This study also showed that $47.8 \%$ had secondary education while $36.2 \%$ of the patients had primary education. These findings are supported by [2] who reported that educational level had no impact on glycemic control. This is because management of type $2 \mathrm{DM}$ is greatly influenced by lifestyle and health education can play a major role in influencing patients' attitude in DM treatment [16].

\subsection{Adherence to Type 2 DM Treatment by the Patients}

This study (Table 3 ) revealed that more than half of the patients (59.4\%) had poor attitude to self-care management. Slightly more than half of the patients (56.5\%) reported poor adherence to type $2 \mathrm{DM}$ treatment as they scored more than 4 scores using the modified Morisky Medication Adherence Scale. The results were similar to studies by [17] [18] [19] [20] [21] which reported that poor adherence to DM treatment was due to poor adoption of Western diet in place of more healthy "traditional" diets, lack of glucose monitoring equipment, complex treatment regimens and confusing instructions provided by the health care providers.

Furthermore, findings of the current study (Table 2) revealed that the majority of the patients (65.9\%) whether on OHD or insulin forgot to take their medication. More than half of the patients (58.7\%) reported stopping taking their medications without informing the doctor, because they felt worse when they took the drugs while $55.8 \%$ of the patients forgot to carry their medicine when they left home. The findings were similar to a study which reported that adherence rates were typically higher among patients with acute conditions than with chronic conditions because of pain patients with acute conditions experienced as opposed to silent but destructive effects of many chronic conditions such as DM which would not compel an individual to seek medical attention [22]. However, some studies still reported good adherence to treatment by majority (85\%) of DM patients [23].

In the present study, more than quarter of the patients $(26.1 \%)$ were on insulin only. Out of 36 patients who were on insulin, $66.6 \%$ reported skipping injec- 
tions due to drugs stock out. These results were similar to the study by [24] who also reported erratic supply of insulin in most Sub-Saharan Africa hospitals where in one of five hospitals and none of six health centers surveyed had a regular insulin supply.

Furthermore, patients who were on diet modification, (23.9\%) reported challenges of not having a choice on the type of food they ate as they had to eat whatever was available in their homes. This was attributed to poor socioeconomic status of many patients in the study and ultimately predisposed them to elevated blood glucose levels and poor adherence to treatment. On the contrary, a study in Botswana, showed that poor self-discipline, lack of information on a healthy diet, eating out in restaurants and financial constraints in accessing the recommended diet by health care practitioners influence adherence to treatment [16]. The study further showed a positive correlation between knowledge of type $2 \mathrm{DM}$ and adherence to treatment. Despite the results of this study indicating poor adherence to treatment (56.5\%), the cross-tabulation between knowledge and adherence showed that, adherence to treatment increased as knowledge increased. Good adherence increased from $32.8 \%$ to $51.9 \%$ and, subsequently, poor adherence dropped from $67.2 \%$ to $48.1 \%$ as knowledge on treatment increased from low to high.

The observed trend was statistically significant as the Chi-square test yielded a p-value of 0.024. Hence, we reject the null hypothesis and conclude that there is an association between knowledge and adherence to treatment among patients with type $2 \mathrm{DM}\left(\mathrm{X}^{2}=5.085, \mathrm{~N}=138, \mathrm{p}<0.05,2\right.$-tailed $)$.

\subsection{Patients' Knowledge about Type 2 Diabetes Mellitus}

In the current study, slightly more than half of the respondents (Figure 2) (55.8\%) had high knowledge of DM despite poor adherence to treatment. The findings were congruent with a study which revealed that, educational level had no impact on glycemic control, though patients with high educational level had better awareness of the complications and a high rate of adherence to treatment [2]. However, another study indicated that patients with knowledge had good adherence to anti-diabetic medication even in a rural setting [25].

Half of the patients $(50 \%)$ reported having been living with DM for 6 years and above, Duration of the disease, influenced adherence to DM treatment positively. The study further revealed that $58.7 \%$ of patients who adhered to treatment had a positive family history of DM and had awareness of the disease. This could be attributed to exposure to DM treatment through helping relatives with the disease and thus when diagnosed with the same condition, the patients would use the knowledge they acquired when there taking care of the relatives to take care of themselves. However, on the contrary, another study by showed that with increasing duration of disease, levels of adherence to treatment decreased due to fear of drugs side effects [26]. This explains why patients who have been on DM treatment for a long time get fed up with the treatment and dietary re- 
gimen and stop adhering to treatment recommendations.

The findings showed that changes in patients' knowledge on diabetes treatment contributed significantly to the regression model while changes in all other variables contributed insignificantly. Changes in knowledge from low to high impacted significantly on the model, with a p-value of 0.031 (OR $=2.180,95 \%$ CI: 1.07, 4.43). However, other variables were not statistically significant, with p-values ranging from 0.461 to 0.972 . Changes in knowledge from low to high increased the odds of adhering to treatment 2.324 times. This meant that patients with high knowledge were twice as likely to adhere to treatment as those with low knowledge.

\subsection{Health Care System}

Good health care services have a direct bearing on adherence to treatment of different ailments. This study showed that slightly more than half of the patients (51.4\%) reported poor health care services and $63 \%$ of reported that oral hypoglycaemic drugs were not always available at the hospital. The study also revealed that among patients who reported poor quality of health care, $42.3 \%$ had good adherence while $57.7 \%$ had poor adherence to treatment. Among patients who reported good health care, good adherence increased to $44.8 \%$ while poor adherence reduced to $55.2 \%$. The findings of the study were consistent with a study, which reported that lack of qualified and skilled health care providers influenced adherence to treatment negatively [27]. Some physicians, pharmacists and nurses did not have the knowledge and competences to initiate patients on the right type $2 \mathrm{DM}$ treatment regimen. Lack of knowledge on the part of the health care provider created a barrier to initiating and monitoring adherence to treatment.

The findings were also consistent with one study, which revealed that a poor relationship between the patient and health care provider adversely influenced adherence to treatment. Poor relationship between patients and health care providers, would not compel a patient to freely ask questions and learn on how best they can take care of themselves [28].

Several studies have showed that effective partnership between patients and healthcare providers enhances improved adherence to treatment, leading reduced healthcare costs, disability and deaths [28]. Patients' attitudes, beliefs, knowledge of the disease, and family support influences adherence to DM management positively. Another study further reported that, patients got frustrated if their preferences in treatment-related decisions were not considered because they feel less empowered [29]. A less empowered patient in relation to treatment decisions negatively influenced attitude towards adherence to treatment. The Chi-square test results yielded a p-value greater than 0.05 , indicating that the observed association was not statistically significant.

Furthermore, less than half of the patients (45.7\%) monitored their blood glucose levels on daily basis and slightly more than half of the patients $(54.3 \%)$ 
reported that they monitored their blood glucose from public hospitals. Two thirds of the patients (67\%) who did not own glucometers monitored their blood glucose from the public hospitals. Of the patients (75\%) who monitored their blood glucose from public hospitals reported that they were not monitoring it regularly due to lack of testing kits and reagents in the laboratory. This also contributed to poor adherence to poor treatment. These results were in line with another study which revealed that many hospitals lacked glucose monitoring equipment. Patients took medicines without monitoring their blood glucose levels, thereby risking going into hypoglycaemia [24]. The results suggest that changes in the health care system from poor to good increased the odds of adhering to treatment by a factor of 1.067 while changes in the attitude of patients towards self-care management from poor to good changed the odds of adhering to treatment by a factor of 1.077 times.

\subsection{Distance to the Hospital}

Physical accessibility of healthcare providers due to distance was another single major challenge to adherence to DM treatment [30]. The current study also showed that the majority of the patients (60.1\%) lived more than $5 \mathrm{~km}$ away from the hospital with only $39.9 \%$ living less than $5 \mathrm{~km}$. Among the respondents who live more than 5 kilometers from the hospital, $48.6 \%$ used public transport to travel, while $41.3 \%$ walked on foot to the hospital. This study showed that most patients who live more than $5 \mathrm{~km}$ from the hospital failed to go to the hospital for regular follow ups thereby negatively influencing adherence to treatment. This could be attributed to a high cost of living in Zambia where the little money patients got was channeled to apparently more important family needs as opposed to individual health care needs [30]. This finding further is in line with the reports which stated that patients who missed their drugs very often were from the lower socio-economic strata because they earn low-income [15] [28]. This is because the earned money was not enough to enable them buy the prescribed meals and fulfill doctors' appointments for regular check-ups hence subjecting patients to poor adherence to treatment. However, on the contrary to the current study, other literature reported that distance barrier in many European countries and in the Eastern Caribbean is no longer a physical hindrance due to improved technology [31]. The binary logistic regression test which was used to analyze the combined impact of adherence to type $2 \mathrm{DM}$ treatment and distance to the hospital established that a change in the distance to the hospital from less than $5 \mathrm{~km}$ to more than $5 \mathrm{~km}$ reduced the odds of adhering to treatment by a factor of 0.768 despite having not being statistically significant $p$ value.

\subsection{Patients' Attitude towards Self-Care Management}

In this study, attitude towards self-care management was assessed using a verified but modified self-care management questionnaire (Table 3). More than half of the patients $(59.4 \%)$ had poor attitude towards self-care management. Fur- 
thermore, most of the patients $(65.3 \%)$ were not checking and recording their blood glucose levels regularly. These findings are consistent with the previous studies which reported that poor adherence to treatment was due to negative attitude to the condition by many patients [3] [8] [32]. Nevertheless, on the contrary, other studies reported that patients who are repeatedly exposed to DM information and lessons about self-care, eventually adjust and learn to effectively control blood glucose to recommended levels, thereby influencing their attitude positively and adhered to treatment [4] [33]. Another study reported fear of needles, as well as side effects of medication such as fatigue and impotence as factors which led to poor attitude to adherence [31]. It is therefore, imperative to intensify trainings by health care providers on self-care management for old and newly diagnosed DM patients to prevent the progression of diabetes complications. Previous studies showed that effective DM self-care management requires an integrated approach involving the patient, family and community members taking an active supportive role to influence positive attitude to DM care [28]. This therefore means that collaboration between patients and health care providers enhances patients' self-care management behaviors to control blood sugar levels.

This study also indicates that adherence to treatment increased as the attitude of patients towards self-care management improved. In patients with poor attitude, good adherence stood at $41.5 \%$. In patients with good attitude, good adherence increased to $46.4 \%$ while poor adherence reduced to $53.6 \%$. The study results are congruent with a study, which reported that DSME generally improved psychosocial and clinical outcomes in patients with DM [34]. This implies that positive attitude towards self-care helps to achieve required glycaemic control. The findings were consistent with assertions of another study, which revealed that the combination of knowledge and attitude improved adherence to treatment where patients displayed both strong knowledge and positive attitude [35]. This could be attributed to continuous health education patients receive whenever they go to seek medical care. Health care providers should therefore be at the patients' disposal for any information needed in order to improve the disease outcome. This can prevent long-term complications and promote quality of life with less health cost.

\subsection{Conclusions}

The purpose of the current study was to assess adherence to type two DM treatment at Monze Mission Hospital, Zambia. Adherence to DM treatment of $80 \%$ or above is recommended for maintaining required glycaemic levels to prevent complications.

This study showed that DM patients have poor adherence to treatment despite being knowledgeable about the disease. Poor adherence to treatment recommendations was attributed to interplay of multifaceted factors such as distance to the hospital, poor attitude towards self-care management and the health care 
system. Most of the patients (63\%) reported drug stock out, financial constraints and poor health habits as the major barriers to adherence to treatment.

The current study rejects the null hypothesis and concludes that there was a relationship between adherence to DM treatment (outcome variable) and knowledge (predictor variable) among patients with type $2 \mathrm{DM}$ as the Chi-square test yielded a p-value of 0.024 .

Consequently, there is need to come up with deliberate strategies to improve adherence to DM treatment among patients attending outpatient medical diabetic clinic such as collaboration between the patients, families and community members and the health care providers to enhance adherence.

Furthermore, human resource capacity building must be embarked on to provide patient education and counseling, promote patients' self-care management behaviour and facilitate the identification and self-care management skills on medication administration, dietary modification and exercise management. There is also need to widen the network of health care facilities through decentralizing the stocking and dispensing of diabetes drugs which must include rural health centers to help serve patients in the peripheral areas. This will help reduce on transport costs thereby enhancing adherence to treatment.

\subsection{Limitations of the Study}

The study was conducted on a limited sample size $(n=138)$ thus the results should be generalized with caution as it only represented views of patients who accessed medical services from Monze Mission hospital. The sample size comprised of patients from the rural and peri-urban settings hence the result may not be generalized for the rest of Zambia. This may not be the case for patients in urban towns, as urban hospitals are well stocked with drugs, blood glucose monitoring testing kits and have readily available health care providers. The data collecting tool used was a closed tool and could not stimulate the respondents to give more required information. Hence, some experiences of the respondents that led to poor adherence to type $2 \mathrm{DM}$ treatment were not provided from the responses.

\subsection{Recommendations}

To strengthen adherence to type $2 \mathrm{DM}$ treatment, the following recommendations were made:

1) The Ministry of Health to improve the supply of antidiabetic drugs both OHAs and insulin, diagnostic and glucose monitoring equipment to all health institutions.

2) Health care providers to be strictly following type 2 DM treatment guidelines to prevent patients from experiencing diabetes related complications.

3) Members of staff managing type $2 \mathrm{DM}$ patients should strength the provision of information Education and Communication (IEC) sessions during the follow-up visit to patients. The IEC should include eating healthy diets, per- 
forming regular exercises, adherence to drugs, frequent monitoring of blood glucose levels and self-care management and keeping appointment schedules.

4) Support groups should be formed in communities in collaboration with the non-governmental organizations, health care providers and family members to assist type $2 \mathrm{DM}$ patients to access recommended treatment services.

5) To have this study replicated using a larger sample in order to evaluate a large-scale representation of patients' adherence to type 2 DM treatment.

\section{Acknowledgements}

The author is grateful to the University of Zambia, School of Nursing Sciences for the mentorship, encouragements rendered before and during this research study.

\section{Conflicts of Interest}

The authors declare no conflicts of interest regarding the publication of this paper.

\section{References}

[1] American Diabetes Association (2010) Diagnosis and Classification of Diabetes Mellitus. Diabetes Care, 33, S62-S69. https://doi.org/10.2337/dc10-S062

[2] Al-Rasheedi, A.A.S. (2014) The Role of Educational Level in Glycemic Control among Patients with Type II Diabetes Mellitus. International Journal of Health Sciences, 8, 177-187. https://doi.org/10.12816/0006084

[3] García-Pérez, L.-E., Alvarez, M., Dilla, T., Gil-Guillén, V. and Orozco-Beltrán, D. (2013) Adherence to Therapies in Patients with Type 2 Diabetes. Diabetes Therapy. Research, Treatment and Education of Diabetes and Related Disorders, 4, 175-194. https://doi.org/10.1007/s13300-013-0034-y

[4] Jackson, I.L., Adibe, M.O., Okonta, M.J. and Ukwe, C.V. (2014) Knowledge of Self-Care among Type 2 Diabetes Patients in Two States of Nigeria. Pharmacy Practice, 12, 404. https://doi.org/10.4321/S1886-36552014000300001

[5] Benhalima, K. and Mathieu, C. (2010) Challenges in the Management of Hyperglycaemia in Type 2 Diabetes. IDF Diabetes Atlas, 4th Edition. 1-7.

[6] Likitha, N.K., Konuru, V., Preeti, V., Sindhu, K. and Bandari, S. (2012) A Study on Medication Adherence in Patients with Diabetes Mellitus along with Hypertension. International Journal of Recent Scientific Research, 3, 192-196.

[7] World Health Organization (2016) Global Report on Diabetes. Geneva.

[8] Pinidiyapathirage, M.J., Kasturiratne, A., Ranawaka, U.K., Gunasekara, D., Wijekoon, N., Medagoda, K. and Wickremasinghe, A.R. (2013) The Burden of Diabetes Mellitus and Impaired Fasting Glucose in an Urban Population of Sri Lanka. Diabetic Medicine, 30, 326-332. https://doi.org/10.1111/dme.12013

[9] Cho, N.H., Whiting, D., Guariguata, L., Montoya, P.A., Forouhi, N., Hambleton, I., Li, R., Majeed, A., Mbanya, J.C., Motala, A., Narayan, V., Ramachandran, A., Rathmann, W., Roglic, G., Shaw, J., Silink, M., Williams, D.R.R. and Zhang, P. (2013) International Diabetes Federation Sixth Edition.

[10] Chatt, C. and Roberts, L. (2010) Access to, and the Delivery of, Free Healthcare in Kanakantapa, Rural Zambia. African Journal of Health Sciences, 17, 15-25. 
[11] Mbanya, J.C.N., Motala, A.A., Sobngwi, E., Assah, F.K. and Enoru, S.T. (2010) Diabetes in Sub-Saharan Africa. The Lancet, 375, 2254-2266. https://doi.org/10.1016/S0140-6736(10)60550-8

[12] Tuei, V.C. (2010) Type 2 Diabetes Mellitus and Obesity in Sub-Saharan Africa. Diabetes/Metabolism Research and Reviews, 26, 433-445.

https://doi.org/10.1002/dmrr.1106

[13] Beran, D., Yudkin, J.S. and de Courten, M. (2005) Access to Care for Patients with Insulin-Requiring Diabetes in Developing Countries: Case Studies of Mozambique and Zambia. Diabetes Care, 28, 2136-2140.

https://doi.org/10.2337/diacare.28.9.2136

[14] Monze Mission Hospital (2016) Monze Mission Hospital Action Plan, Monze.

[15] Sharma, T., Kalra, J., Dhasmana, D. and Basera, H. (2014) Poor Adherence to Treatment: A Major Challenge in Diabetes. Journal, Indian Academy of Clinical Medicine, 15, 26-29.

[16] Ganiyu, A.B., Langalibalele, H.M., Nomsa, H.M., Indiran, G. and Gboyega, A.O. (2013) Non-Adherence to Diet and Exercise Recommendations amongst Patients with Type 2 Diabetes Mellitus Attending Extension II Clinic in Botswana. African Journal of Primary Health Care and Family Medicine, 5, 457. https://doi.org/10.4102/phcfm.v5i1.457

[17] Banu, S., Prasanth, Y.M. and Anjana, K. (2014) Adherence to Treatment among Type 2 Diabetes Mellitus Patients Visiting a Tertiary Care Hospital in Mangalore. International Journal of Biomedical Research, 5, 254-256. https://doi.org/10.7439/ijbr.v5i4.582

[18] Antoine, S.L., Pieper, D., Mathes, T. and Eikermann, M. (2014) Improving the Adherence of Type 2 Diabetes Mellitus Patients with Pharmacy Care: A Systematic Review of Randomized Controlled Trials. BMC Endocrine Disorders, 14, 53. https://doi.org/10.1186/1472-6823-14-53

[19] Musenge, E.M. (2014) Glycaemic Control in Diabetic Patients in Zambia. The Pan African Medical Journal, 19, 354. https://doi.org/10.11604/pamj.2014.19.354.5264

[20] Mukherjee, S., Sharmasarkar, B. and Das, K.K. (2013) Compliance to Anti-Diabetic Drugs: Observations from the Diabetic Clinic of a Medical College in Kolkata, India. Journal of Clinical and Diagnostic Research, 7, 661-665. https://doi.org/10.7860/JCDR/2013/5352.2876

[21] Brown, M.T. and Bussell, J.K. (2011) Medication Adherence: WHO Cares? Mayo Clinic Proceedings, 86, 304-314. https://doi.org/10.4065/mcp.2010.0575

[22] Bogner, H.R., Morales, K.H., de Vries, H.F. and Cappola, A.R. (2012) Integrated Management of Type 2 Diabetes Mellitus and Depression Treatment to Improve Medication Adherence: A Randomized Controlled Trial. Annals of Family Medicine, 10, 15-22. https://doi.org/10.1370/afm.1344

[23] Abebaw, M., Messele, A., Hailu, M. and Zewdu, F. (2016) Adherence and Associated Factors towards Anti diabetic Medication among Type II Diabetic Patients on Follow-Up at University of Gondar Hospital, Northwest Ethiopia. Advances in Nursing, 2016, Article ID: 8579157. https://doi.org/10.1155/2016/8579157

[24] Hall, V., Henriksen, O. and Lohse, N.T. (2011) Diabetes in Sub Saharan Africa 1999-2011: Epidemiology and Public Health Implications. A Systematic Review. BMC Public Health, 11, Article No. 564. https://doi.org/10.1186/1471-2458-11-564

[25] Bagonza, J., Rutebemberwa, E. and Bazeyo, W. (2015) Adherence to Anti Diabetic Medication among Patients with Diabetes in Eastern Uganda; a Cross Sectional Study. BMC Health Services Research, 15, Article No. 168. 
https://doi.org/10.1186/s12913-015-0820-5

[26] Parajuli, J., Saleh, F., Thapa, N. and Ali, L. (2014) Factors Associated with Nonadherence to Diet and Physical Activity among Nepalese Type 2 Diabetes Patients; a Cross Sectional Study. BMC Research Notes, 7, Article No. 758.

https://doi.org/10.1186/1756-0500-7-758

[27] Alkhaifi, M., Ghaitha, A.K. and Thord, T. (2015) Barriers in Initiating Insulin Treatment in Type 2 Diabetes Mellitus among Physicians in Wilayat of Bowsher in Oman. Journal of Family Medicine \& Community Health, 2, 1034.

[28] Steyl, T. and Phillips, J. (2014) Management of Type 2 Diabetes Mellitus: Adherence Challenges in Environments of Low Socio-Economic Status. African Journal of Primary Health Care \& Family Medicine, 6, a713.

https://doi.org/10.4102/phcfm.v6i1.713

[29] World Health Organization (2003) Improving Adherence Rates: Guidance for Countries.

[30] Central Statistical Office (2013) Zambia Demographic and Health Survey. 2013-14.

[31] Mcguire, M., Freyder, M. and Ricketts, P. (2013) A Review of Diabetes Treatment Adherence Interventions for the Eastern Caribbean.

[32] Baptista, D.R., Wiens, A., Pontarolo, R., Regis, L., Reis, W.C.T. and Correr, C.J. (2016) The Chronic Care Model for Type 2 Diabetes: A Systematic Review. Diabetology \& Metabolic Syndrome, 8, 7. https://doi.org/10.1186/s13098-015-0119-z

[33] Powers, M.A., Bardsley, J., Cypress, M., Duker, P., Funnell, M.M., Hess Fischl, A. and Vivian, E. (2015) Diabetes Self-Management Education and Support in Type 2 Diabetes: A Joint Position Statement of the American Diabetes Association, the American Association of Diabetes Educators, and the Academy of Nutrition and Dietetics. Journal of the Academy of Nutrition and Dietetics, 115, 1323-1334. https://doi.org/10.1016/j.jand.2015.05.012

[34] Stellefson, M., Dipnarine, K. and Stopka, C. (2013) The Chronic Care Model and Diabetes Management in US Primary Care Settings: A Systematic Review. Preventing Chronic Disease, 10, E26. https://doi.org/10.5888/pcd10.120180

[35] Martínez, Y.V., Prado-Aguilar, C.A., Rascón-Pacheco, R.A. and Valdivia-Martínez, J.J. (2008) Quality of Life Associated with Treatment Adherence in Patients with Type 2 Diabetes: A Cross-Sectional Study. BMC Health Services Research, 8, Article No. 164. https://doi.org/10.1186/1472-6963-8-164 